Journal of History Culture and Art Research

Revue des Recherches en Histoire Culture et Art

مجلة البحوث التاريخية والثقافية و الفنية
Vol. 2, No. 2, June 2013

Copyright (C) Karabuk University

http://kutaksam.karabuk.edu.tr/index.php

Özel Sayı/Special Issue

(English Studies)

DOI: 10.7596/taksad.v2i2.251

\title{
Life Events and Negative Religious Coping
}

\section{Sema ERYÜCEL ${ }^{*}$}

\begin{abstract}
Recently, insufficiency of secular coping methods has drawn the attention of researchers towards religious coping methods. While the parts about theory and model cover an important place in the literature, experimental studies are rapidly going on. Although religious coping was initially interpreted as positive, experimental studies reveal that it also has negative forms. The purpose of this study, in which qualitative research methods were used, is to define the components of religious coping. Semi structured interview was used among 42 participants, 9 war veterans from Association of Turkish Disabled War Veterans, Martyrs, their Widows and Orphans Ankara Branch, and 9 relatives of martyrs from the Association of Martyrs' Families Ankara Branch, totaling 60 volunteer participants between the ages 25 and 65 with snowball sampling method. It was discovered that 29 of the participants used negative religious coping and the participants who only used negative religious coping were studied in this research. Upon recording the interviews with the aid of a recorder, the researched typed the script of the interviews. The qualitative analysis of the collected data was done in MAXODA 11 computer program.
\end{abstract}

Keywords: Life events, Religious coping, Negative religious coping

\footnotetext{
*Ankara University, Faculty of Divinity.
} 


\section{Introduction}

A majority of people (96\%) in the researches carried out abroad point out that they believe in God or a universal spirit (Gallup and Lindsay, 1999). Similarly, in the researches done in our country, 94\%-97\% of people define themselves as religious (Ayten, 2012). However, the relationship between psychology and religion is still a pile of data stocked in a contradictory and complex way (Lonczak., Clifasefi, Blume, and Donovan; 2006). The study which is quoted most about the relation between religion and mental health is perhaps Bergin's study in 1983. It was revised and quoted by 24 different researches. A positive and beneficial relation between religion and mental health at a rate of $47 \%$ was found in Bergin's study while a relation that is harmful and affecting the health negatively at the rate of $23 \%$ existed. Additionally, 30\% without any relation was found in the study (Bergan, 2000; Ellison, 1991; Ellison, 1995; Ellison et al., 2001; Ellison and Levin, 1998; Hunsberger, Pratt and Prancer, 2001; Koenig and Larson, 2001a; Koenig, McCullough and Larson, 2001b; Pargament, 1997; Schnittker, 2001; Strawbridge et al., 1998).

These studies reflect the researches done by Bergin in 1983. Meta-analysis studies done by Hackney and Sveers in 2003 are the same as Bergin's studies conducted 20 years ago. Religion has positive, negative and irrelevant effects on psychological results. Only negative religious components were studied in this article.

While beneficial coping method is positive and effective, harmful coping method is negative and ineffective. While there is learning, development and inner transformation with the faced event in positive religious coping, there are the life event's evaluation as a punishment from god, not being able to accept it and the idea of self-sufficiency (Pargamnet, 1997). A growing number of studies support the fact that these two coping styles have different effects on health, adaptation, and morale (Loewenthal, MacLeod, Goldblatt, Lubitsh, and Valentine, 2000; Pargament, Koenig, Tarakeshwar, and Hahn, 2001; Pargament et al. 1998). Incompatible religious copins is a form of serious anger at the existence of the problem (e.g. Why is there a problem like that?, I should not experience such a problem, I cannot accept the existence of problems in my life) (Hackney and Sveers, 2003).

Although religious involvement is high in negative religious coping, a weak relationship with God, opinion that the world is a dangerous place, and meaninglessness are among the common findings (Pargamnet and oth. 1998). This weak religious background shows behaviors like "the belief of being punished by God, the belief others caused the problem, being doubtful of God's power, spiritual unrest, dissatisfaction, self-driven religious coping, and dissatisfaction with the 
relationships with religious people (Pargament et al., 1998; Koenig et al., 1998; Bjorck and Thurman 2007; Bjorck and Kim, 2009).

One of the important components of negative religious coping is the way the individual got attached to his/her parents. Four attachment types, which are secure, anxious, ambivalent, and avoidant, were stated in Bowlby's attachment theory (1973, 1988). In Bowlby's latest practices (1988), the individual's attachment style is highly connected with his perception of God and religion and understanding the source of the problem during stressful times. It was found out in the studies done on religious coping styles and attachment types that attachment types apart from secure attachment is related to negative religious coping (Cooper, Bruce, Harman, Boccaccını 2009; Schottenbauer et al. 2006).

Another variable in this issue is the image of God. People whose image of god is punitive, judgmental and distant prefer negative religious coping methods while coping with the life events when they encounter (Maynard, Gorsuch, and Bjorck 2001).

Furthermore, some people may keep their expectations high considering their involvement in religious issues (e.g. I pray a lot, so I should not have any problem). The idea their expectations have not been fulfilled often results in a negative change in the image of God and negative religious coping (Bjorck and Kim 2009). Having concrete expectations by the individuals who prefer negative religious coping is a common phenomenon. Even while praying, the aim is not to set a communication with the Creator, but to gain concrete results (Janssen et al., 2000; Janssen and Banziger, 2003).

Negative religious coping does not fancy social support and is about being dissatisfied with people (Pargament 1997, Pargament et al. 1998, Pargament et al. 2000). However, people often need the assistance of others during stressful times (Caplan, 1981; Winemiller, Mitchell, Sutliff, and Cline, 1993).

In addition, it has been found out that negative religious coping is connected with religious dissent. Individuals experiencing religious dissent, unrest and dissatisfaction may feel that they have been abandoned by God and that they are being punished for their sins by God (George et al., 2002). Such feelings may bring about such consequences as giving up religion as a mechanism of coping, or desperation, praying to God for something that is not realistic and even for miracles.

Along with dissenting with God, the dissenting person may also feel uncomfortable and reject religious communities and items associated with those groups (Sorri, Henriksson and Loennqvist, 1996). Those rejected feelings may entirely turn into hated beliefs and this can be the main source of the stress (Pargament, 2002).

It has been revealed that negative religious coping is highly connected with major depression (Bjorck, Kim; 2009), low life standards, more psychological symptoms and 
discourtesy and severity towards others. Negative religious coping is also strongly linked with depression, anxiety, emotional stress and posttraumatic stress (Pargament et al. 1998, Pargament et al. 2001a).

All in all, although a relationship between fewer cases of depression as a result of increasing religiousness is expected, negative religious coping (e.g. anger) evokes undesired consequences like depression, anxiety and suicide (Exline et al., 2000; Koenig Cohen, Blazer and Piper, 1992).

The term "event" was specially preferred based on the literature instead of using "negative life events and traumatic life events" for the events in coping period since standpoint is decisive in determining if an event is good or bad and acceptable or unacceptable. It is seen in the literature that different reactions are given to similar difficulties and that different outcomes are yielded associated with these reactions. We can categorize the life events during the coping period into three based on the literature:

a) Coping the with problems in relationships ( e.g. problems with family, friend, etc. relationships)

b) Loss ( e.g. disease, death of a beloved one, being handicapped, divorce, bankruptcy and economic losses, social status)

c) Threat, the individuals' life being under serious threat and therefore having to make drastic changes in his/her life ( e.g. war, terror, natural disaster, migration) (McCrae, 1984; Bjorck and Cohen, 1993; Maynard et al. 2001).

\section{Method}

Generally, a religious coping scale or a similar tool is used in the studies about religious coping. The religious coping method is tried to be understood through one scale. Actually, a multi-directional analysis is needed since religious coping is a multi-component one (Cole, 2005; Sherman, 2001; Sherman, Plante, Simonton, Latif, and Anaissie, 2009; Tarakeshwar, 2006; Zwingman C., Wirtz, M., Muller, C., Korber, J., and Murken, S., 2006). The religious coping scale makes an overall measurement. However, a more detailed analysis is required in many specific life events. A qualitative research method was preferred in this study since it enables to catch the meaning of the real life events and to see multiple interpretations of the same events based on the perceptions of the participants.

Once questioning the description of the life experiences, people turn into stories like in the losses (Hurwitz, B., Greenhalgh, T., and Skultans,V. 2004). Thus, responses to the interview questions are often shaped by the stories (Stewart, 2011). On the other hand, descriptions or solutions of life events are located in "stories of personal experience" (Labov, 1972). Hence, personal experiences are always the closest focal point of the story analysis (Creswell, 1998). In the study, narrative analysis model which is one of the qualitative 
research models and interview as a means of data collection were preferred. Then, content analysis of the conducted interviews was done.

\section{Participants}

Participants consist of 60 adult volunteers between the ages of 25-65 who are considered to represent the research. 42 of the participants were determined by snowball method. Within the scope of the death of a beloved one, families whose children were killed as a result of terrorism were studied and 9 families of martyrs at the Association of Martyrs' Families Ankara Branch were interviewed. Furthermore, to understand the state of life's being under threat which is considered as the most serious one of the life events, 9 volunteer veterans at the Association of Turkish Disabled War Veterans, Martyrs, their Widows and Orphans Ankara Branch were included in the research. The most basic criteria sought among the participants is the fact that they have experienced a life event in which they lost the meaning of life, or a crisis and severe disappointment and the fact that they can share these experiences. However, in order to provide a variety in the study, it was made sure that the participants were from different life events (e.g. relationships, loss, threat), the distribution of women and men, different education levels and different socio-economic levels. In the findings part, the names of the participants were changed.

\section{Research Questions}

The first aim of the study was to create a questionnaire. In this respect, created by Pargament and his colleagues, a short religious coping scale consisting of 14 articles, 7 of which were aimed at measuring positive religious coping and 7 of which were intended to measure negative religious coping (Pargament et al., 1998) was revised along with qualitative religious-spiritual coping and problem-solving questions (Nelson-Becker, 2004; Stewart, 2011; Nakonz, 2008; King, Speck and Thomas, 1995; Pargament, 1997; Fowler; 1981). Then, a question pool containing 85 articles was formed. Then, with the help of this pool, a questionnaire form consisting of 10 articles were designed considering 5 fundamentals of religious coping which are meaning, control, consolation, social support and transformation (Pargament; 1997). A presentation consisting of religious coping, fundamentals of religious coping, questions from questionnaires that was done through qualitative research methods in the literature and finally religious coping form that was designed by the researcher was given to a group including the thesis advisor and about 10 people of MA and PhD students. Subsequently, the researcher asked their comments on the issue.

In this respect, thanks to the suggestion of two expert psychologists, one psychiatrist and two psychology of religion experts, the two questions that were asked in a body were decided to be asked separately and were decided to make them more comprehensible by making some changes on them. Prior to the piloting, the 
research questions were shared with one professor of psychiatry, one professor of psychology of religion, one professor of clinical psychology, one professor of religion education, one professor of religion sociology, one professor of sociology, one professor of logos, two associate professors of religion of psychology and one associate professor of religion sociology totaling ten academicians.

In addition to the prepared questions, it was decided to check whether the fact that the participant had more than one crisis and disappointment in his/her life had any influence on the selection of coping method. Aldo, one question article was agreed to be changed. After the piloting the study on seven people, the research was initiated agreeing that there was no item in the research questions that did not work.

\section{Procedure}

Participants who were suitable for the study were included in the research thanks to personal contacts by using the snowball method. Some of the participants were co-workers and school mates. Furthermore, interviews were conducted with nine relatives of martyrs at the Association of Martyrs' Families Ankara Branch and with veterans at the Association of Turkish Disabled War Veterans, Martyrs, their Widows and Orphans Ankara Branch. At the beginning of the face-to-face interview, each participant was asked to fill out an information and permission form to record the interview of them (Appendix 1). Each participant was given a nick name so as to protect the privacy. The interviews took place at the jointlydetermined times and locations (workplace or home of the participant, or an outdoor place). The interviews took about one hour while there were also ones that lasted at least half an hour and two hours at most. Moreover, follow-up questions were made use of in order to extend the questions. Those recorded interviews were also transcribed. Initially, content analysis was done so as to determine the topics and categories. The first analysis was interpreted after reading them again and again and was categorized by taking notes. The responses of each participant were principally identified and discussed with the advisor. The content analysis yielded topics and categories like image of God, acceptance, coping behaviors, social support and inner transformation. Later, the data was coded again and again in the computer program MAXQDA 11 as an open code, an axis code and finally a selective code. The analysis of all participants was done after the coding was repeated by two researchers.

\section{Findings}

The aim of this research is to define various life events (e.g. relationships, losses, and life-threatening situations) and religious variables in a negative religious coping period.

11 males and 18 females, totaling 29, participated in the study. As for the marital status of the participants, 2 of them live away from their spouses, 3 of them are single, 16 of them are married, 5 of them are divorced and 3 of them lost their spouses. The education level 
of them is that 4 of them have never been to school while 5 of them have primary school, 7 of them have high school, 8 of them have university and 5 of them graduate school degrees. 4 people between the ages of 25 and 30, 14 people between the ages of 30 and 40, 5 people between the ages of 40 and 50,1 person between the ages of 50 and 60 and 5 people between the ages of 60 and 65 participated in this research. This data belongs to the participants who only used negative religious coping.

\section{Life events that were defined by the participants}

In order to understand the coping process, one firstly should analyze the life events that are defined by the participants. Among the most popular live events identified by the participants, various losses tops the list with 16 people. Then, there are 5 participants with problems in various relationships, and lastly, 1 participant with life-threatening situations which is considered to be the most serious in the literature. In terms of losses, there are 8 incidents of health, 8 incidents of death of a beloved one, 7 incidents of divorce, and 4 incidents of economic problems. The reason why the number of life events is not higher than that of participants is that some of the participants shared more than one life event.

Candan, aged 37, was asked by one of her relatives to vouch for him since she was a civil servant told about the event: "I vouched for my aunt's husband in his purchase costing about 10.000-15.000 Turkish Liras. Then, he used this vouching for his other commercial businesses. This incident is the one I can call a crisis. Firstly, the bank gave away 10 thousand TL for each of my signature. Then, it was $100.000 \mathrm{TL}$, and from 200.000 TL up to 300.000 TL was loaned by the bank without informing me. These digits were 7-8 years ago and the bank gave the loan with a single signature. It was called an open loan. Vouching for somebody was unlimited in commercial vouching, which I did not know." (Candan, aged 37)

Gülden explained the events she faced with: "I am the mother of a handicapped. I have epilepsy, cancer, high blood pressure and many others. It would be easier to count the ones I don't have, but a life would not be possible without crisis" (Gülden, aged 49).

Ulya, aged 35, is a computer engineer and works at a company as a manager. She shared the death of her husband that was 8 years ago: "My husband and I studied at the same university. We were in love and got married when I was 23. My daughter was 2 and half and I was 5 and months pregnant. He was working as an engineer at an important institution for the strategy of the country. He was on a business trip. He was killed in a traffic accident, which

still stays as a mystery. It was very painful. I went through a very tough time. The house of my mother had a garden and they could hear me cry outside. 2 and half years passed like that and there was not a single day when I did not cry." (Ulya, aged 35) 


\section{Participants' interpretation of the life events}

The fact that the experienced situation is a damage and loss, anger, seeing themselves as a victim, not being able to make sense, blaming others, seeing it as a divine punishment and regrets were some of the common findings among the participants who used negative religious coping methods

Gülden, whose 13-year-old son is an autistic, points out about this issue: "There is no known reason for autism. Some of them say it is caused by intelligence. I do not know if he is very intelligent, but he learned how to read at the age of 3 on his own. He may have a good intelligence, but I think there is no sense if you cannot use it. I wish he was a normal boy and we lived the life normally" (Gülden,aged 49).

Veysel's vocal cords were taken out in a goiter operation he underwent and he thinks the reason is "a mistake of the reasons and he could not seek his rights." (Veysel, aged 38)

Güler's husband is in prison for intentional homicide within a berdel* case. With her two children, she does not have any income. She has never been to school. Neither her own family nor the family of her husband took care of her. She even got involved with beggary once. Then, a woman working as an expert at the Presidency of Religious Affairs noticed her. She filled petition forms to be sent to charity organizations on behalf of Güler and now she is living on the financial aids coming from the state. When we asked Güler how she interpreted the events she experienced, she answered: "How can I explain it? I am confused. Sometimes, I think that it is a test coming from God and I also ask Why me?, What did I do to deserve this? I am also a young woman. I have my own desires and wishes. I would like my husband to take care of me and I would like to take care of my home and kids, but I cannot" ( Güler, aged 32).

*berdel: the marriage in which the son and daughter of a family gets married with the son and daughter of another family at the same time.

\section{Religious bonds of the participants}

Along with participants who considered themselves as faithful, there were also ones who felt no connection with any religion or ones who said that they questioned religious beliefs and religion was just a sample of induction. However, among faithful participants in this group, superficiality in religious life and a frightened image of God were common.

Aylin: "I have not felt that I belong to any religion since my childhood, or I feel I belong to all religions. In other words, I can go to a mosque or a church and pray there. All is the same for me. I do not care Islam or Quran, but I care good words. I can enjoy hearing good words everywhere. I don’t take my spiritual pleasure from religions (Aylin, aged 39). 
Alp, aged 28, thinks that: "I do not have any blind belief. (...) Let's say students studying Quran die after the building collapses. And God takes them to heaven, but when people die in a foam party, they are punished by God. Actually, this is an induction. I do not have a concept of two-footed creator as it is in religions, in Torah. Jesus is the God in Bible. I do not have a concept of God who constantly intervenes with people's lives. Zeus does the same job and Egyptians have a lot of legends. Religion does not fundamentally change. It changes shape."

Ahmet, a religious commissary aged 42, said that: "While making decisions in life, we definitely consider the religious orders. However, we have a superficial religiousness, which is caused by weakness in our belied. It is superficial. We fulfill certain requirements of the religion, but it is just superficial."

Mehmet, a food engineer aged 33, said: "If you ask me to make a religious talk, I can do that, but when faced with those situations, I also outcry. I cannot think in a healthy way then. That is, my spiritual side is not that strong."

\section{Coping behaviors of the participants}

Participants often used secular coping methods. There were also participants who believed that nobody and nothing could help them with the situation they are in. Moreover, there were also the ones who made use of coping methods like having a talk with those people who have are in similar situations along with participants who talked about their wishes such as I love money a lot and it makes me happy, I wish I could get rid of depression, I would like to love and be love, etc.

Fulya, aged 46, was diagnosed with skin cancer and was told she would live for another 1,5-2 years. She says being with her friends and walking around with them were therapeutic for her. "Definitely, being with my friends helped a lot. I walked around a lot and saw new sights with them. Where have I been? I went to theatre, cinema and cafes with them as a normal individual. I lost all my hair and everyone looked at me, but my skin color also changed. I was not pessimistic. I did not pretend like everything was perfect as well. I said I had a shot today and let's see what would happen. I lost my hair, but I went to the hairdresser's to get only three pieces of hair blow-dried. He asked me which direction I wanted it and I told him to the most difficult one since he already could not make a bun (laughs). I took a picture with my blow-dried hair. I cannot escape it because that is also me."

Firdevs' sister was stabbed to death by a hitman hired by her husband. Although it was not legally proved that the murder was masterminded by her husband, Firdevs is sure that it was done by her husband and she thinks that nothing will ever stop her pain: "Nothing can ease my pain. I was very sad and was about to go mad. My sister's murder always occupied 
my mind. How did the murderer get inside? What did my sister do when she saw her? Was she scared? Did she expect any help? I could not sleep until the mornings. (Firdevs, aged 65)

\section{The Perceived Religious/Social Support}

Among the participants using negative religious coping, there were also ones, despite being few, who pointed out that they got positive support from their environment along with definitions of support such as dissatisfaction with people, not accepting any support and using depressions medicine as the best support. In coping process, family is the primary source of social support. However, the father of Erkan, a civil engineer, left his family when Erkan was a kindergarten kid. His mother got obsession as a result of this incident. When asked from whom he got help, Erkan answered: "I like taking depression pills. It makes me relaxed, but it makes me sleepy. I could not fix its dose because I had no job and social security since I finished the school at the age of 29 and I found a job very late." (Erkan, aged 32)

Gülden, who has a son aged 13-14, talked about her story of not getting help from anybody: "I gave birth 10 years after I got married. My husband did not want a child and neither did I. I had a hard time persuading my husband. After having a handicapped baby, he blamed me a lot in the period of acceptance. He spent 4 months in the psychiatry clinic and had arguments with me for years. Even the grandmother called my baby as insane. I could not get any help and had very tough days. (Gülden, aged 49)

Ulya, who lost her husband when she was 27: "I visited many experts, but received no help. They wanted to give medication to me, but I was pregnant and breastfeeding, I could not. I started the medication three years later, but never benefited from it. I put on about 10-13 kilos. The medication just freezes everything. You do not feel anything. Since you feel nothing, time passes without realizing it. What relaxed me most was talking with the people with the same sorrow. I got angry with the advices of others silently asking What did you experience to give me those advices? When I talked to the people who lost their spouses at a young age, I felt relaxed. It helped me think there were other people like me. I was not the only one on earth. That made me calm (Ulya, aged 37).

\section{Inner change}

Participants also mentioned some positive changes along with stating negative changes in their inner worlds and priorities in life, discontent with life, thinking of committing suicide and no change, awareness of self and the Creator was pretty limited.

Candan, whose vouching was used to get some other loans by one of her relatives said: "I feel tired. I am just tired. I feel like 65." (Candan, aged 37)

For Filiz, a civil engineer who got divorced from her husband, the life event that can be called as a crisis was the divorce and she said about the change in her inner world: "I got 
lost in that period while trying to decide on the things. I was lost. I still have some problems." (Filiz, aged 31)

Erkan: "I am not happy with my life. I would consider unless it were a sin. Since I am a faithful person, I can never do that, but I consider it." (Erkan, aged 32)

Zehra who split up with her fiancée: "At first, my relationship with God was not very good. I was angry with God at the beginning of this event. I was angry with both my family and God. What my family dictated and I internalized was that Zehra did not make any mistakes and she did not have troubles. Even God would protect her because she had been a religious girl since childhood. I think it is wrong to rationalize everything and set connections between them as anything can happen to a person." (Zehra, aged 32)

"Spirituality was my priority, but I have changed a lot. I am not as I was in the past, which means my manners were not strong. It is not right to find excuses for these events. I think it just did not fit with me." (Mehmet, aged 33)

Interpretation of the event as a deficiency and punishment, the opinion that it was because of others, not being able to make sense of the event, not being able to accept, accepting in a comparative gratitude (e.g. comparing himself with the others), seeing the event as a punishment from God and dissatisfaction are among the findings among the participants that use negative religious coping. Deism and atheism can be seen with some of the participants and they use secular coping strategies in the coping process. However, despite not being one of our research questions, high religious participation, but a weak bond with God can be seen. It is interesting to see that those who took religion education at high school or university and an important number ( 8 people) of those who are involved in religion education and religious service (e.g. imam, preacher, Quran teacher, teacher of religious culture and morale) are in this group. Furthermore, among the participants of long-term (7-10 years) antidepressant use and adverse changes in the spiritual life, dissatisfaction with life, and suicidal ideation are among the findings. However, as it is in Aylin's (39) case, the fact that life events raised her in terms of spirituality is present here as data of positive religious coping.

\section{Discussion}

Since the question whether life events are connected with the coping reactions of people or not is studied in the research, different life events were made us of in this study. Among the participants (10 people) whose lives are being under threat, which is considered as the most serious one of the life events in the literature, only one participant used negative religious coping. Also, among the participants experiencing similar problems, although there are ones using positive religious coping, there are also participants who use negative coping. The coping process is, of course, a process consisting of many components such as personal, 
social, mental ones. Therefore, problem solving process cannot be formulated. However, in the coping process, in the evaluation of losses, damages benefit, and earnings of the event, point of views, labor and acceptance brought about different results, which is an important finding of this study.

Negative religious coping (punitive conception of God, God, negative attitudes towards members of the clergy and religious groups) found to be associated with poorer physical health, the deteriorating quality of life, increased depression (Koenig et al., 1998) and poor emotional function (e.g. dissatisfaction, discontent, ) (Bjorck and Thurman 2007). For example, Ahmet (42): "I have been using antidepressants for 10 years and I had panic attack right after depression." Zehra (32) was diagnosed with depression after an event she experienced and she still thinks her dreams have not come true: "My depressions started at that time and I used medication regularly for 6 years. I have recently been to the psychiatrist and the doctor said depression has just repeated itself and now I have just started the medication again.” ( Zehra, 32). Gülten: “Acceptance period was very tough. My husband could not accept the fact that our son was an autistic and he was hospitalized at the psychiatry clinic for four months. It was not easy for me, either. At first, my husband used to warn me a lot. When I saw a boy the same age as mine, he says I used to stare at him with anger and jealousy."

In negative religious coping, there is an approach claiming the world is a dangerous place (Pargament et al. 1998). With respect to this issue, Mehmet (33) says: "I keep my fists clenched even while I am walking just in case something comes up from around." Candan (37) claims: I cannot trust anyone. Even while I am walking on the street, I want to use a rearview mirror to see who is framing up what behind me (laughs). I cannot trust anybody. It is very difficult to live without trusting someone. I have lost all of it. It has turned into a psychological disorder for me. Candan asked me whether her name will be mentioned during the interview a couple of times.

Together with participants who answered the question how you would describe yourself in terms of religion as they did not feel they belonged to a religion and they questioned the religions (Maynard et al. 2001; Pargament et al. 1998), it was interesting to see that 8 of 10 participants who took religion education in high school and at university were in this group. Furthermore, despite not being among the research questions, there were participants whose religious involvement was high (Bjorck, Kim; 2009 Pargament et al. 2001).

The question how they would interpret the event they face as a process of punishment-learning or a blessing is one of the decisive questions of the study. Almost all of the participants using negative religious coping interpret the situation as a punishment or test. Moreover, anger at people and God, focusing on the existence 
of the problem instead of trying to solve it and weak relationship with God can be seen among the participants using negative religious coping (Bjorck and Thurman 2007). For example, Ulya (35) said: "I know I have to right to do this, but I am angry with God (cries). When my husband was alive, I used to get up to pray twice a night. What did I do to deserve this? I said to myself. I know I should not do it, but I told it myself." Mehmet (33) stated: "I was more concentrated prior to this event. The divorce affected my spiritual life negatively. If you ask me to give a religious talk, I can do that, but when I face with those situations, I also outcry and rebel. I cannot think in a healthy way then. That is, my spiritual side is not that strong."

It was found out that participants using negative religious coping was associated with not accepting any support, dissatisfaction with people and rigidity with other people (Pargament 1997, Pargament et al. 1998, Pargament et al. 2000). Also, together with discontent with God, rejecting religious communities and items that remind the person of them and dissatisfaction are commonly faced (Sorri et al. 1996). These rejected feelings may turn into beliefs that are not loved, which can eventually be the source of the stress (Pargament, 2002). For example, Aslihan (35), who has a handicapped child, said that: "My friends who visited me said that since people cannot reach high positions thanks to prayers, God may let those situations happen. Then, I got furious. Am I person without any praying? Is that why god put me in this situation? I used to get angry with them. (...) I used to burst into tears then all around the day".

Although it includes a number of shapes (e.g. understanding, being grateful for what is given, and believing) as a method of religious coping, it can be said that prayer is the most common religious coping method for health problems and stress (Spilka et al. 2003; Hood et al., 1996, p. 399). Prayer is divided into four categories in terms of its purpose. The basic theme of the prayer in the form of wishing and demanding is the affect, or outcome, or the occurrence of some concrete things. It is related to negative religious coping (Janssen et al., 2000; Janssen and Banziger, 2003). A significant bond between this prayer type and somatization of metal disorders was found (Lonczak et al. 2006). Aslihan (35) was informed in the $2^{\text {nd }}-3^{\text {rd }}$ month of her pregnancy as a result of the tests that the baby was handicapped. As the pregnancy went on, more detailed information was provided with her about the handicaps of the baby. For example, right hand and right leg were longer than left hand and left leg respectively. The baby did not have a uvula and even there was no transition between the hemispheres of brains. All the predictions were true at the end. However, Aslihan said: "I was saying that I prayed a lot and my God was testing me. There will be a big surprise and there will be no handicap. Everybody will be wrong. (...) When I was pregnant, I thought God way testing me and I would have a very nice surprise, but it was not the case at the end. Despite all that data, Aslihan's interpretation of the situation that the baby would not be a handicapped one because she prayed a lot is an indication of her not thinking in a healthy 
way. As a result, wishing-begging, one of the praying types, is highly associated with religious coping methods (Park and Cohen 1993; Zeidner and Hammer 1992; Pargament et al. 1994) and somatization of a worsening mental disorder (Lonczak ve diğ. 2006). The purpose of the prayer should not be fulfilling the needs of a person by Gold.

One of the most important results of life events is the fact that it enables inner change (Pargament et al. 2000a). The fact that there was no change in participants using negative religious coping and negative change in the spiritual life, dissatisfaction with life and desire to commit suicide appeared.

Participants using negative religious coping often blamed other people and expressed their dissatisfaction. For example, as for the reason why Emel (32) had problems with the family of her husband: "The reason for all these is their discourtesy and rudeness. I do not deserve this" (cries). The reason of Mehmet's divorce is: "Disagreement between the families and the selfishness of the opposite". They cannot make sense of the event they experienced or they see that event as a loss and damage. While there was no one who acknowledged the event, a large number of them expressed that they could not accept it. Zehra (32) said the following regarding her not accepting the situation regarding after her break-up with her fiancée: "I rebelled a lot. There were even times that I gave up praying in that period. I always said that I lived honestly and I did my best. Is that what I deserve? No, I did not deserve this."

Although increasing religiousness is expected to cause less depression, negative religious coping (e.g. anger) evokes harmful results like depression, anxiety and suicide (Exline et al., 2000; Koenig et al.1992).

\section{Conclusion}

As a result, what literature means by negative religious coping is actually not being able to cope. The most decisive point of coping process is the individual's maintaining his/her harmony with life.

* Participants using negative religious coping often lost their adaptation with life.

* In negative religious coping, there is the idea that I am self-sufficient, I do not need any support from anybody including God or somebody, including God shall solve my problem. During the problem-solving process, the need for either endeavor or the belief in big support is being ignored.

* There is a relationship between punitive, judgmental and distant image of God and negative religious coping.

* Not being able to accept the life event and why me? type of questions are negative variables on coping period. 
* The support taken from God is relatively limited in the process of negative religious coping. The result does not change for the participants whose religious involvement is high.

* With participants using negative religious coping, it was seen that the experienced life event does not offer an inner change or that it causes negative variables.

\section{References}

Ayten, Ali (2012). Tanrı'ya Siğınmak. İstanbul: İz Yayıncılık

Bergan, A. (2000). "Religiosity and life satisfaction." Activities, Adaption and Aging, 24, 23 34.

Bergin, A. E. (1983). "Religiosity and mental health: A critical reevaluation and metaanalysis." Professional Psychology: Research and Practice, 14, 170-184.

Bjorck, Jeffrey P., And L. H. Cohen. (1993). "Coping With Threats, Losses, And Challenges." Journal of Social and Clinical Psychology 12 (1), 56-72.

Bjorck, Jeffrey P., and L. L. Klewicki. (1997). "The effects of stressor type on projected coping." Journal of Traumatic Stress 10 (3), 481-97.

Bjorck, J. P., and Thurman, J. W. (2007). "Negative Life Events, Patterns Of Positive And Negative Religious Coping, and Psychological Functioning." Journal for The Scientific Study of Religion, 46, 159-167.

Bjorck Jeff P., Kim Jean-Woo (2009). "Religious coping, religious support, and psychological functioning among short-term missionaries." Mental Health, Religion and Culture 12(7), 611-626

Bowlby, J. (1973). Attachment and Loss. Vol. 2. Separation. New York: Basic Books.

Bowlby, J. (1988). A Secure Base: Parent-Child Attachment and Healthy Human Development. New York: Basic Books.

Butter Eric M., Pargament Kenneth I.,(2003) "Development of a Model For Clinical Assessment Of Religious Coping İnitial Validation of The Process Evaluation Model." Mental Health, Religion and Culture 6 (2): 175-194

Carpenter, B. N., and Scott, S. M. (1992). Interpersonal aspects of coping. In B. N. Carpenter (Ed.), Personal coping: Theory, research, and application (pp. 93-109). Westport, CT: Praeger.

Cole, B.S. (2005). "Spiritually-focused psychotherapy for people diagnosed with cancer: A pilot study." Mental Health, Religion and Culture, 8, 217-226.

Cooper, Laura B. , Bruce A. Jerry, Harman Marsha J., And Boccaccinı Marcus (2009) "Differentıated Styles Of Attachment To God And Varying Religious Coping Efforts" 
Creswell, J.W. (1998). Qualitative inquiry and research design: Choosing among five traditions. Thousand Oaks, CA: Sage.

Ellison, C. G. (1991). "Religious involvement and subjective well-being." Journal of Health and Social Behavior, 32, 80-99.

Ellison, C. G. (1995). "Race, religious involvement and depressive symptomatology in a southeastern US community." Social Science and Medicine, 40, 156 1-1572.

Ellison, C. G., and Levin, J. S. (1998). "The religion-health connection: Evidence, theory, and future directions." Health Education and Behavior, 25, 700-720.

Ellison, C. G., Boardman, J. D., Williams, D. R., and Jackson, J. S. (2001). "Religious involvement, stress, and mental health: Findings from the 1995 Detroit Area Study." Social Forces, 80.1, 2 15-249.

Exline, J. J., Yali, A. M., and Sanderson, W. C. (2000). "Guilt, discord, and alienation: The role of religious strain in depression and suicidality." Journal of Clinical Psychology,56,1481-1496.

Fowler, J. W. (1981). Stages of Faith: The psychology ofhuman development and the quest for meaning. San Francisco: Harper and Row.

Gallup, Jr. G., and Lindsay, M. D. (1999). Surveying The Religious Landscape: Trends in Us Beliefs. Harrisburg, Pa: Morehouse Publishing

George, L. K., Ellison, C. G., and Larson, D. B. (2002). "Explaining the relationships between religious involvement and health." Psychological Inquiry, 13, 190-200.

Hackney, C. H., and Sanders, G. S. (2003). "Religiosity and mental health: A meta-analysis of recent studies." Journal for the Scientific Study of Religion, 42, 43-55.

Hood, R. W. Jr., B. Spilka, B. Hunsberger, and R. Gorsuch. (1996). The psychology of religion: An Empirical Approach. New York: Guilford Publications.

Hunsberger, B., Pratt, M., and Pancer, M. S. (2001). "Religious versus nonreligious socialization: Does religious background have implications for adjustment." The International Journal for the Psychology of Religion, 11, 105-128

Janssen, J., and Prins, M. H. (2000). "The abstract image of God: The case of the Dutch youth". Archives de Sciences Sociales des Religions, 109, 31-48.

Janssen, J., and Ba“nziger, S. (2003). "Praying as a universalising variable." Archive for the Psychology of Religion, 25, 100-112.

King,M., Speck, P.,and Thomas,A., (1995) The Royal Free Interiew for Religious and Spritual Beliefs: Development and Standardization. Psychological Medicine, 25, 1125-1134

Koenig, H.G., Cohen, H.J., Blazer, D.G., Pieper, C., Meador, K.G., Shelp, F., et al.. (1992). "Religious Coping And Depression Among Elderly, Hospitalised Medically İll Men". American Journal of Psychiatry, 149, 1693-1700. 
Koenig, H. G., K. I. Pargament, and J. Nielsen. (1998). "Religious coping and health status in medically ill hospitalized older adults." Journal of Nervous and Mental Disease 186(9):51321.

Koenig, H. G., and Larson, D. B. (2001a). "Religion and mental health: Evidence for an association." International Review of Psychiatry, 13, 67-78.

Koenig, H. G., McCullough, M. E., and Larson, D.B. (2001b). Handbook of religion and health. New York: Oxford University Press.

Loewenthal, K. M., MacLeod, A. K., Goldblatt, V., Lubitsh, G., and Valentine, J. D. (2000). "Comfort and joy? Religion, cognition, and mood in Protestants and Jews under stress." Cognition and Emotion, 14, 355-374.

Lonczak Heather S., Clifasefi Seema L., Marlatt G. Alan, Blume Arthur W., and Donovan Dennis M. (2006) "Religious Coping And Psychological Functioning in a Correctional Population." Mental Health, Religion and Culture; 9(2): 171-192

Maynard, E. A., R. L. Gorsuch, and J. P. Bjorck. (2001). Religious coping style, concept of God, and personal religious variables in threat, loss, and challenge. Journal for the Scientific Study of Religion, 65-75

McCrae, R. R. (1984). Situational Determinants Of Coping Responses: Loss, Threat, And Challenge. Journal of Personality and Social Psychology 46 (4), 919-28.

McCrae, R. R. (1992). Situational determinants of coping. In B. N. Carpenter (Ed.), Personal coping: Theory, research, and application (pp. 65-76). Westport, CT: Praeger.

McCracken, L. M. (1998). "Learning to live with the pain: Acceptance of pain predicts adjustment in persons with chronic pain." Pain, 74,21-27.

Nakonz, Jonas and Wai Yan Shik Angela (2008). "And All Your Problems Are Gone: Religious Coping Strategies Among Philippine Migrant Workers In Hong Kong." Mental Health, Religionve Culture, 12, 25-38

Nelson-Becker, Holly B 2004 Spiritual, Religious, Nonspiritual, and Nonreligious Narratives in Marginalized Older Adults: A Typology of Coping Styles. Journal of Religion, Spirituality andAging Vol. 17, No. 1/2, ,pp. 21-38

Pargament, K.I., Ishler, K., Dubow, E., Stanik, P., Rouiller, R., Crowe, P., et al.. (1994). "Methods of Religious Coping With The Gulf War: Cross-Sectional And Longitudinal Analyses." Journal for The Scientific Study of Religion, 33, 347-361.

Pargament, K.I. (1997). The Psychology of Religion And Coping: Theory, Research, And Practice. New York: Guilford Press.

Pargament, K. I., Smith, B. W., Koenig, H. G., and Perez, L. (1998). "Patterns Of Positive And Negative Religious Coping With Major Life Stressors." Journal for The Scientific Study of Religion, 37, 710-724

Pargament, K. I. And K. I. Maton. (2000). Religion İn American Life: A Community Psychology Perspective. In Handbook of Community Psychology, Edited By J. Rappaport And E. Seidman, Pp. 495-522. Dordrecht, Netherlands: Kluwer Academic Publishers. 
Pargament Kenneth I., Tarakeshwar Nalını, Ellıson Chrıstopher G., Wulff Ke1th M. (2001) Religious Coping Among the Religious: The Relationships Between Religious Coping and Well-Being in a National Sample of Presbyterian Clergy, Elders, and Members. Journal for The Scientific Study of Religion 40:3 497-513

Pargament, K. I. (2002). The bitter and the sweet: An evaluation of the costs and benefits of religiousness. Psychological Inquiry, 13, 168-181.

Park, C.L., and Cohen, L.H. (1993). Religious and Nonreligious Coping With The Death Of A Friend. Cognitive Therapy and Research, 17, 561-577.

Schnittker, J. (2001). "When is faith enough? The effects of religious involvement on depression." Journal for the Scientific Study of Religion, 40, 393-411.

Schottenbauer Michele A., Dougan Bonnie Klimes , Rodriguez Benjamin F. ,Arnkoff Diane B. , Glass Carol R. and Lasalle V. Holland (2006) "Attachment And Affective Resolution Following A Stressful Event: General And Religious Coping As Possible Mediators." Mental Health, Religion ve Culture ; 9(5): 448-471

Sherman, A.C., and Simonton, S. (2001). Religious involvement among cancer patients: Associations with adjustment and quality of life. In T.G. Plante, and A.C. Sherman (Eds.), Faith and health: Psychological perspective (pp. 167-194). New York: Guildford Press

Sherman, A.C., Plante, T.G., Simonton, S., Latif, U., and Anaissie, E.J. (2009). "Prospective study of religious coping among patients undergoing autologous stem cell transportation." Journal of Behavioral Medicine, 32, 118128.

Sorri, H., Henriksson, M., and Loennqvist, J. (1996). "Religiosity and suicide: Findings from a nationwide psychological autopsy study." Crisis, 17, 123-127.

Spilka, B., Hood Jr, R. W., Hunsberger, B., and Gorsuch, R. L. (2003). The Psychology of Religion: An Empirical Approach (3rd ed.), New York: The Guilford Press.

Stewart Katıe A. (2011). "The Spıritual Framework Of Copıng Through The Voices Of Cancer Survivor Narratives" Omega, Vol. 63(1) 45-77, 2011

Strawbridge, W. J., Shema, S. J., Cohen, R. D., Roberts, R. E., and Kaplan, G. A. (1998). "Religiosity buffers the effects of some stressors on depression but exacerbates others." Journal of Gerontology, 53B, 118-126.

Tarakeshwar, N., Vanderwerker, L. C., Paulk, E., Pearce, M. J., Kasl, S. V., and Prigerson, H. G. (2006). "Religious coping is associated with the quality of life of patients with advanced cancer." Journal of Palliative Medicine, 9(3), 646-657.

Yin, Robert K. (2011) Qualitive Research From Start to Finish. The Gullford Press New York London

Zeidner, M. and A. L. Hammer (1992) Coping with missile attack: Resources, strategies and outcomes. Journal of Personality 60, 709-746. 


\section{APPENDIX}

Hello, I am Sema Eryücel. I am a PhD student at the department of sociology of religion at the Faculty of Theology. I am studying on the thesis whose subject is "Life Events and Spiritual Coping". Within the scope of the dissertation, I am researching on relationships (e.g. mobbing), losses (e.g. death, disease, being handicapped) and threatening life events (e.g. natural disaster, war, terror). First of all, I would like to thank you for your participation in the research. I think the interview will take about 30-45 minutes. You can end the interview whenever you would like. The information about the interview will only be kept by me and my advisor. I would like to answer any questions you have before starting the interview. If you feel ready, we can start.

1- Have you had any moments in your life when you felt a deep disappointment, crisis or there was no meaning of life?

2- What was the reason of that situation?

3- What was the meaning of this situation or did you give any meaning to it?

4- Did you accept that period?

5- If you could not accept, what were the factors behind it?

6- How would you define yourself spiritually?

7- Sometimes, when we face a life event, we ask questions like God, what am I learning with this?, What is this punishment for?, Why me? and put meanings on them. What did you say to yourself for this situation?

8- What helped you or what was good for you in this period?

9- From whom did you get help?

$10-$ Were there any changes in your spiritual life?

11- Were there any changes in your priorities in life?

12- When you look back to all you have gone through, are you satisfied with your life? 